Bulgarian Academy of Sciences. Space Research and Technology Institute.

Aerospace Research in Bulgaria. 31, 2019, Sofia

DOI: https://doi.org/10.3897/arb.v31.e05

\title{
COSMIC RAY AND SOLAR ACTIVITY INFLUENCES ON LONG-TERM VARIATIONS OF CAVE CLIMATE SYSTEMS
}

\author{
Alexey Stoev, Penka Stoeva \\ Space Research and Technology Institute - Bulgarian Academy of Sciences \\ e-mail: stoev52@abv.bg,penm@abv.bg
}

Keywords: Cosmic ray, Solar activity, Cave climate, Temperature changes

\begin{abstract}
During the analysis of solar activity impact on climate, the emphasis is placed on temperature changes. Earth's atmosphere is a dynamical system with a complex variability in space and time. Due to the fact that caves in Karst preserve the long term environmental changes, the investigation of the in-caves' atmospheric parameters and their variations with time becomes very important in the last quarter of century.

In this paper we investigate the temporal evolution of the temperature and pressure of the ground atmospheric layer in the region of two Bulgarian caves: Snezhanka (Pazardjik region) and Uhlovitsa (Smolyan region), during the period 2005-2017. We show that thermal and mass exchange of the caves' air with the environment has significant temporal variations. On annual basis the thermodynamical parameters of the observed caves behaves as a barotropic fluid, in which the air density depends only on atmospheric pressure. As a result, the temporal evolution of in-caves' pressure and temperature change synchronously with time. The observed 11-year signal could be attributed to the heliospheric modulation of galactic cosmic ray $(G C R)$ intensity, which modulates the ozone and humidity near the tropopause and correspondingly the strength of the atmospheric greenhouse effect. Our study helps to clarify the influence of helio-geophysical factors on the state of the lower atmosphere.
\end{abstract}

\section{Introduction}

It has been known for a long time that solar activity and disturbances it causes in the interplanetary environment affect different processes in all layers of the Earth's atmosphere. Among the other external factors influencing Earth's climate are galactic cosmic rays (GCRs) and space dust, the latter of which controls the total energy transferred from the Sun to the Earth's atmosphere. With no doubt, the comfortable conditions supporting the existence of life on the planet, are obviously ensured by the amount of the total solar irradiance (TSI) reaching the planetary surface. The instrumental measurements, however, do not support the idea for a significant deviation of TSI from its recently observed values, while paleoclimatic records give evidences for dramatic changes of Earth's climate 
during the planetary evolution. Moreover, the reconstruction of TSI from $7000 \mathrm{BC}$ up to $500 \mathrm{AD}$ shows that the amplitude of its variations does not exceeds $1 \%$ [1].

Much bigger changes are observed in solar UV radiation (in the interval $175 \div 200 \mathrm{~nm}$ (Schumann-Runge bands) $\sim 6 \%$. This motivates some scientists [2] to suggest that the heating of the stratosphere by UV radiation can be dynamically transported down to the troposphere. Meanwhile, it has been revealed the increased climate sensitivity to the chemical and dynamical conditions in the upper troposphere - lower stratosphere region [3,4]. The external forcing, which easily reach these altitudes are GCRs, what gives a hint that they could somehow influence the surface climate. One of the proposed mechanisms includes GCR influence on the clouds' cover, which could modulate the amount of solar radiation reaching the planetary surface [5]. The more generalized relationship is given by Lev Dorman [6]:

(solar activity cycles + long-term changes in the geomagnetic field) $\rightarrow$ $\rightarrow$ (CR long term modulation in the Heliosphere + long term variation of cutoff rigidity) $\rightarrow \rightarrow$ (long term variation of clouds covering and aerosols + atmospheric electric field effects) $\rightarrow$ climate change.

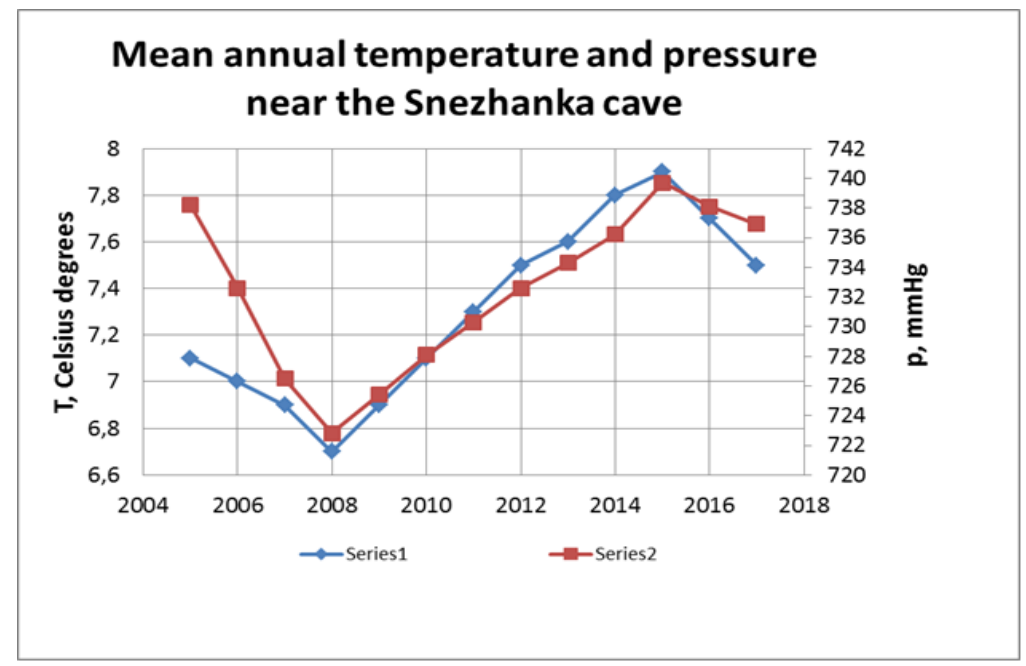

Fig. 1. Mean annual temperature $\boldsymbol{T}$ (series 1) and barometric pressure $\boldsymbol{p}$ (series 2) near the Snezhanka cave (Pazardjik region, Bulgaria) in the period 2005-2017

However, the CERN laboratory experiment reveals that the impact of cosmic radiation in cloud's formation is negligible [7]. Meanwhile, it has been proposed a new hypothesis [8] according to which the GCR influence on the near tropopause ozone drives corresponding variation of the water vapour in the upper 
troposphere. The impact of the latter ensures $90 \%$ of the greenhouses power of the whole water content in the atmosphere [9], modulating in such a way the climate conditions near the planetary surface.

\section{Experimental modelling of complex monitoring for sustainable development of protected Karst territories}

The aim of the work is to design experiment and create a model for complex monitoring of protected Karst territories as a basis for specialized research, management and sustainable development and education. The Karst territories were identified and measurements of the different parameters required for the complex monitoring model were made.

Studying microclimate in caves and influence of solar and geomagnetic activity on processes there, we have investigated relations between cave air temperature and: sunspot number, Ap max index, surface temperature and pressure near about the caves and found very good correlation [10].

In this work we want to investigate the influence of $\mathrm{CR}$ on cave microclimate. We compare average annual changes in pressure and temperature of the ground atmosphere in the region of caves Uhlovitsa (Smolyan) and Snezhanka (Pazardzhik), Bulgaria in the period 2005-2015 and Cosmic Ray (CR) variations from the neutron monitor in Athens, Greece (geographic latitude $37.97^{\circ} \mathrm{N}$, geographic longitude $23.78^{\circ} \mathrm{E}$, altitude $260 \mathrm{~m}$ a.s.l.).

The studies of the microclimate in caves give additional perspective on the variations of climatic parameters with time. This paper presents information for variations of near surface temperature and pressure measured near two Bulgarian caves, but close to their entrances, where the exchange with the outside environment is still quite good. The examination of the records reveals the existence of quasi-decadal variations in the temperature and pressure during the observed period 2005-2017. The results and possible explanation of these variations are presented in the following sections of the work.

\section{Data and results}

The temperature and pressure has been measured by automatic meteorological stations in the region of two Bulgarian caves Snezhanka (Pazardzhik region) and Uhlovitsa (Smolyan region) - close to the cave entrances, during the period 2005-2017. The results are presented on Fig. 1 and Fig. 2.

Data of Galactic Cosmic Ray variability has been taken from NMDB: Real-Time Database for high-resolution Neutron Monitor measurements (http://www01.nmdb.eu/). We use such a station which is located closest to South Bulgaria where the studied caves are. This is the neutron monitor in Athens, Greece (geographic latitude $37.97^{\circ} \mathrm{N}$, geographic longitude $23.78^{\circ} \mathrm{E}$, altitude 
$260 \mathrm{~m}$ a.s.1.). The instrument is Standard 6-NM64 neutron monitor with geomagnetic threshold - effective vertical cut-off rigidity (Epoch 2000.0) 8.53 GV (see http://www01.nmdb. eu/station/athn/).

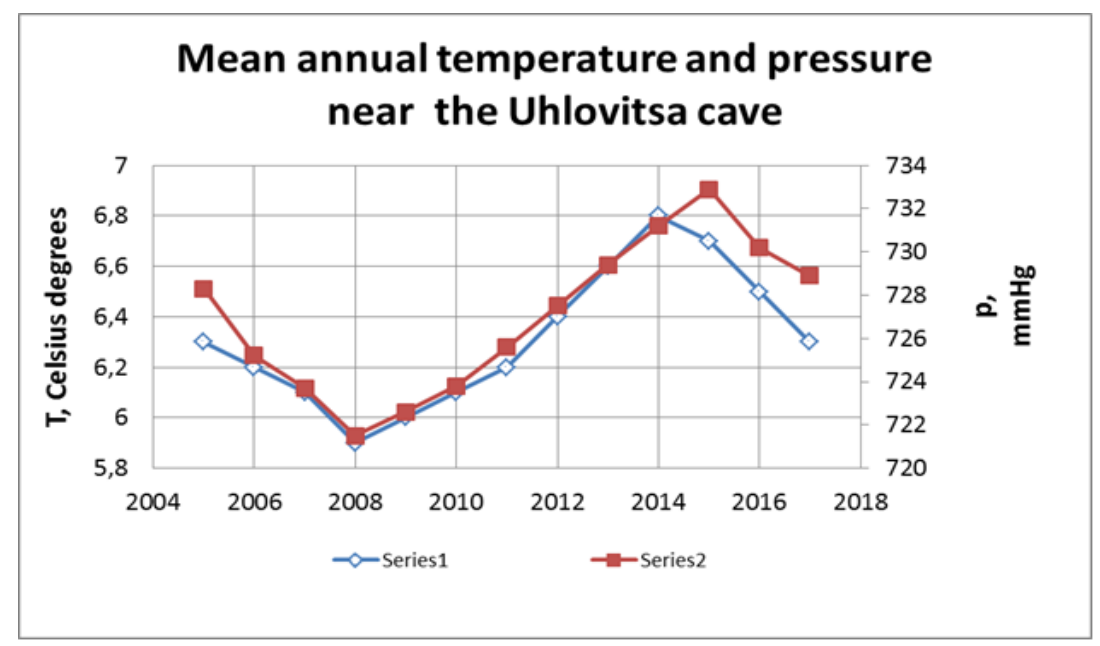

Fig. 2. Mean annual temperature $\boldsymbol{T}$ (series1) and barometric pressure $\boldsymbol{p}$ (series 2) near the Uhlovitsa cave (Smolyan region, Bulgaria) in the period 2005-2017

Sunspot numbers and planetary Ap index are taken from the SILSO (Sunspot Index and Long-term Solar Observations, URL: http://www.sidc.be/silso/datafiles) of World Data Center for the production, preservation and dissemination of the international sunspot number, situated in Royal Observatory of Belgium, Brussels.

On Fig. 3a are shown the courses of GCRs (Athens Neutron Monitor) and the monthly smoothed sunspot numbers (SSN). On Fig. 3b are presented the monthly smoothed Ap index and SSN during the period 2001-2018.

\section{Analysis and interpretation}

We have compared the mean annual values of air temperature and pressure in the region of two Bulgarian caves - Snezhanka (Pazardzhik region) and Uhlovitsa (Smolyan region) (Fig. 1 and Fig. 2). It is easily noticed that the temperature and pressure have a well pronounced minimum during the period of low solar activity, followed by a corresponding peak near the maximum of sunspot's numbers. Due to the modulation of GCR intensity by the 11-year solar cycle, in period of minimum solar activity more GCR are allowed to penetrate the heliosphere and correspondingly their intensity, measured in the Earth's environment, is maximal (see Fig. 3). Oppositely, when the Sun is more active, the 
higher density of solar wind and the stronger magnetic field carried by them act as a barrier for less energetic GCR - disrupting their propagation in the heliosphere.

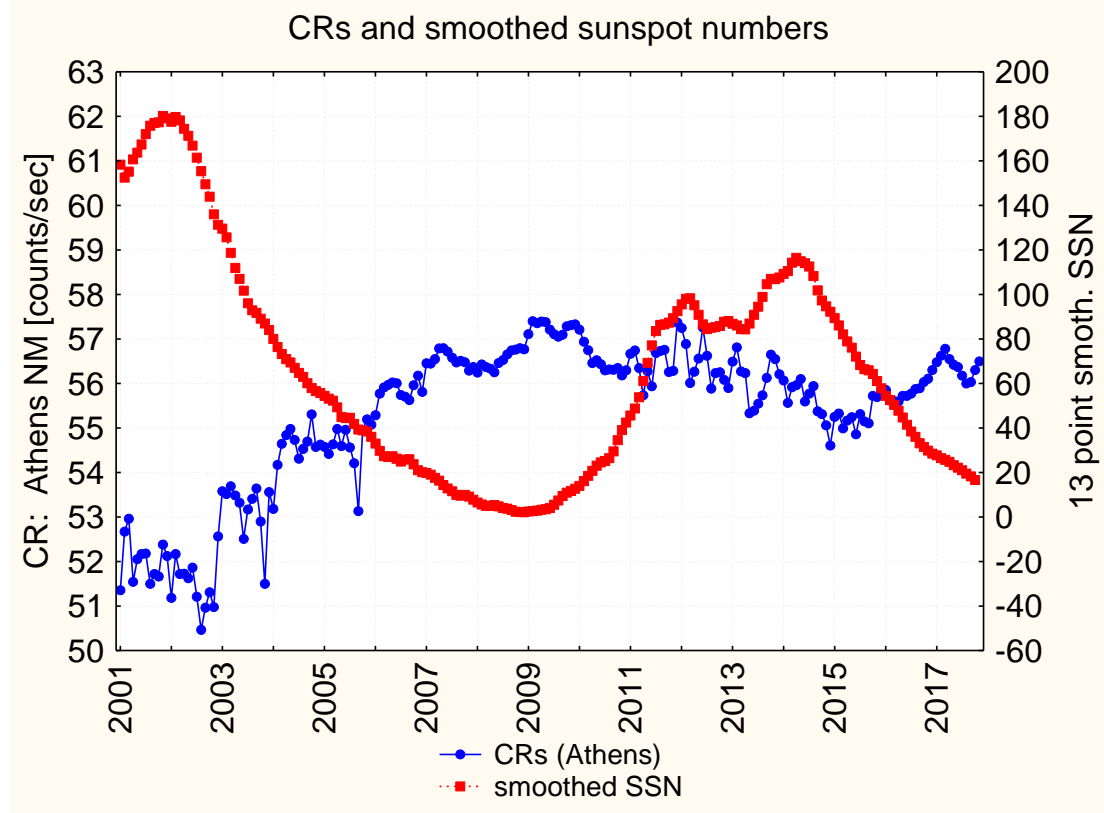

Fig. 3a. Variations of smoothed sunspot numbers (SSN) (http://www.sidc.be/silso/datafiles) and neutron component of cosmic rays during the period 2001-2018

On Fig. 3a is clearly shown the correlation between solar and geomagnetic activity, while Fig. 3a demonstrates the anti-correlation between solar activity and the intensity of galactic cosmic rays. The time lag or the relaxation of natural processes relative to solar activity is also noticeably seen on Fig. 3.

The existence of solar signal in climate parameters is reported from many authors and several hypotheses are attempting to explain this quasi-periodicity. An intriguing moment in our data is the covariance between surface air temperature and pressure. This means that the caves are filtering the baroclinic disturbances, which are typical for the real troposphere, especially at mid-latitudes. More specifically, in baroclinic atmosphere the relation between pressure and temperature in not linear, due to the fact that besides from pressure the atmospheric density depends also on the temperature of air masses. Temperature and pressure covariates with time (see Fig. 1 and Fig. 2). This suggests that ground atmospheric layer near the cave entrances behaves as a barotropic fluid, in which air density depends only on the atmospheric pressure. 
The next question, which should be elucidated, is the decadal variability of the temperature and pressure with time. As mentioned in the introduction, the amplitude of the quasi-decadal variations of TSI is less than 1\% [1], which suggests either existence on amplifying mechanism(s) of solar electromagnetic radiation reaching the planetary surface, or impact from other external influence. There are a lot of studies reporting for an existence of a relation between GCR and climatic and ionization state of the environment $[11,12]$.

A plausible hypothesis for GCR influence on the Earth's climatic conditions is presented in $[8,13]$ and an explanation of our results with it is described in the following section.

\section{Explanation of results with mechanism of Kilifarska}

The relation between energetic particles and middle atmospheric ozone has been reported in several studies $[14,15]$. However, Kilifarska [8, 13] has revealed for the first time the important role of the secondary electrons, produced by GCRs in the Regener-Pfotzer maximum [16], for activation ofion-molecular reactions and ozone production just above the tropopause [17]. Moreover, the GCR effect is not homogeneously distributed over the globe, due to the spatially heterogeneous geomagnetic field [18]. This specificity of GCR forcing is able to explain the regional character of climate variability, which couldn't be said for the other mechanisms.

According to $[8,13]$ the $\mathrm{O}_{3}$ variations above the tropopause affect its temperature and consequently - the moist adiabatic lapse rate. For example, during the minimum of solar activity - the increased level of GCR should produce more ozone in the lower stratosphere, which warms the tropopause. This would stabilize the upper troposphere, due to the increased wet adiabatic lapse rate. However, the vertical motions in a stably stratified atmosphere are strongly suppressed [19]. Consequently, after some time the upper troposphere will become drier and its greenhouse power will be reduced. Taking into account that $90 \%$ of the greenhouse effect of the whole water vapour in the atmosphere is due to the upper tropospheric water vapour [9] - one might expect a surface cooling in periods of high CR intensity (respectively low solar activity).

Coming back to our Fig. 1 and Fig. 2, we could attribute the depression in near surface temperature and pressure in both caves to the increased ozone density in the lower stratosphere and consequently - to the increased static stability and reduced humidity in the upper troposphere. This, in turn, diminishes the greenhouse effect of the water vapour cooling the Earth's surface. Oppositely, the temperature-pressure peaks, during the maximum of $24^{\text {th }}$ solar cycle, could be attributed to the depleted $\mathrm{O}_{3}$ density and increased water vapour near the tropopause, which warms the surface through the strengthened greenhouse effect. 


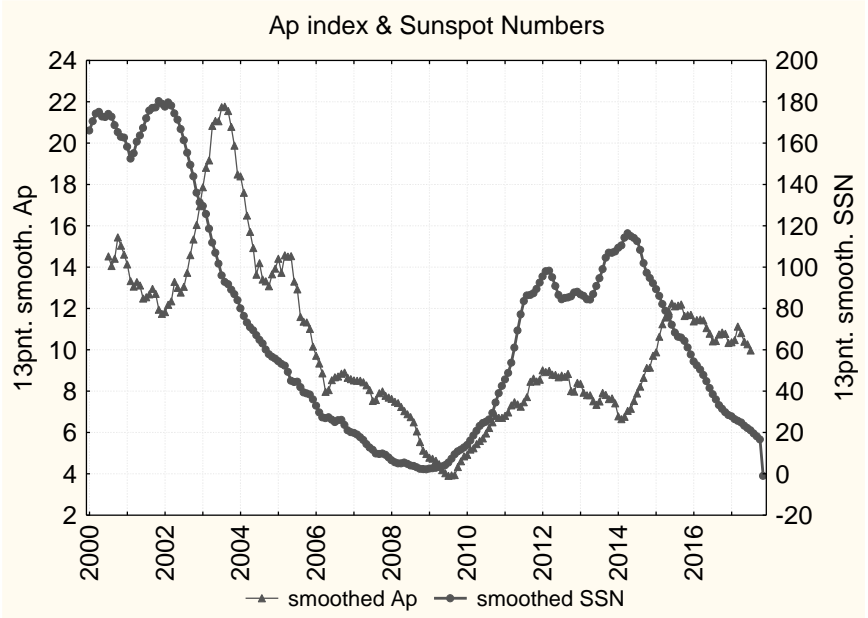

Fig. 3b. Variations of smoothed sunspot numbers (SSN) (http://www.sidc.be/silso/datafiles) and planetary geomagnetic Ap index during the period 2001-2018

\section{Discussion and conclusion}

In the last quarter of the century, the problem of the impact of the low atmosphere with its dynamic baric and temperature fields on the microclimate of caves in Karst was particularly interesting. An important aspect in the study of the change of the thermodynamic state of the cave atmosphere is the search for processes directly or indirectly affecting the air temperature in the zone of constant temperatures of the caves. The paper shows that models of ground atmosphere circulation and thermo and mass exchange with the air volume in the caves have energetically significant spatio-temporal variations. Their main thermodynamic parameters are mainly related to the dynamic efficiency of atmospheric movements in the low atmosphere. In turn, they are strongly influenced by the rapid change of Earth's cosmic rays and the evolution of the actual solar cycle.

Subject of this work is the detected relationship between annual changes in the temperature and pressure of the ground atmospheric layer near the entrances of Snezhanka (Pazardjik caves) and Uhlovitsa (Smolyan region) caves, Bulgaria in the period 2005-2017.The preliminary data analysis reveals the existence of an 11year solar signal. This temperature variability could be attributed to the influence of GCR on the secondary ionisation in the Regener-Pfotzer maximum [15] and furthermore on the lower stratospheric ozone. The latter, in turn, affects the humidity beneath the tropopause and consequently - the strength of the greenhouse effect, because more than $60 \%$ of it belongs to the water vapour [20], and particularly to its amount in the upper troposphere [9]. The ozone - humidity variations and their imprint on the surface temperature seems to be a key factor for 
understanding the temporal and spatial specificity of recently observed climate changes $[13,21,22]$.This is like that because the changes in solar luminosity are small and slowly [23] to be a factor in the observed climate variations.

\section{Acknowledgements}

We acknowledge the NMDB database (www.nmdb.eu) founded under the European Union's FP7 programme (Contract no. 213007), and the PIs of individual neutron monitors for providing data.

\section{References}

1. Shapiro, A. I., W. Schmutz, E. Rozanov, M. Schoell, and M. Haberreiter. A new approach to the long-term reconstruction of the solar irradiance leads to large historical solar forcing. Astronomy\&Astrophysics, 2011, 529, A67, 1-8, doi:10.1051/0004-6361/201016173.

2. Kilifarska, N. A. and J. D. Haigh. The impact of solar variability on the middle atmosphere in present-day and pre-industrial atmospheres, J. Atmos. Solar-Terr. Phys, 2005, 67, 3, 241-49.

3. Kilifarska, N. A. Solar variability and climate-UTLS amplification of solar signal, Sun and Geosphere, 2006, 1, 1, 51-55.

4. Damiani-Badache, C., J. P. Rozelot, K. Coughlin, and N. Kilifarska. Influence of the UTLS region on the astrolabes solar signal measurements, Mon. Not. Royal Astron. Soc., 2007, 380, 2, 609-14, doi:10.1111/j.1365-2966.2007.12079.x.

5. Svensmark, H. Cosmic rays and Earth's climate. Space Sci. Rev., 2000, 93, 175-85.

6. Dorman, L. CR and other space climate factors influenced on the Earth's climate change. Electronic Scientific Edition Almanac Space and Time Special issue 'The Earth Planet System', Earth in Space, COST 803 program, 2012, 1, 1, UDK 524.1: 58.057:57.045:551.581.1.

7. Dunne, E. M., et al. Global atmospheric particle formation from CERN CLOUD measurements, Science, 2016, 354, 6316, 1119-24, doi:10.1126/science.aaf2649.

8. Kilifarska, N. A. Bi-decadal solar influence on climate, mediated by near tropopause ozone, J. Atmos. Solar Terr. Phys, 2015, 136, 216-30.

9. Inamdar, A. K., Ramanathan V., and Loeb N. G. Satellite observations of the water vapour greenhouse effect and column longwave cooling rates: Relative roles of the continuum and vibration-rotation to pure rotation bands, J. Geophys. Res., 2004, 10, D06104, doi:10.1029/2003JD003980.

10. Stoeva, P. and Stoev A. Cave air temperature response to climate and solar and geomagnetic activity. Memorie della Società Astron. Ital., 2005, 76, N4, 1042-47.

11. Eroshenko, E., P. I. Y. Velinov, A. Belov, V. Yanke, E. Pletnikov et al. Relationships between neutron fluxes and rain flows, Adv. Space Res., 2010, 46, $637-41$.

12. Velinov, P. I. Y., N. A. Smirnova, and V. A. Vlascov. Hybrid quadri-ionic model of the lower ionosphere, Adv. Space Res., 1984, 4, 1, 123-30. 
13. Kilifarska, N. A. Hemispherical asymmetry of the lower stratospheric O3 response to galactic cosmic rays forcing, ACS Earth and Space Chemistry, 2017, 1, 80-88, DOI: 10.1021/acsearthspacechem.6b00009.

14. Tassev, Y., Kilifarska, N., and Tomova, D. Statistical analysis of solar proton flux influence on thermodynamics of middle atmosphere in the north hemisphere, C. R. Acad. Bulg. Sci., 2014, 67, 1, 95-100.

15. Kilifarska, N. A. Long-term variations in the stratospheric winter time ozone variability - 22 year cycle, C. R. Acad. Bulg. Sci., 2011, 64, 6, 867-74.

16. Velinov, P. I. Y. and L. Mateev. Effects of galactic cosmic rays and high energy particles on the parameters of the global atmospheric electrical circuit, Geomagnetism and Aeronomy, 1990, 30, 4, 554-57.

17. Kilifarska, N.A. An autocatalytic cycle for ozone production in the lower stratosphere initiated by galactic cosmic rays, C. R. Acad. Bulg. Sci., 2013, 66, 2, 243-52.

18. Velinov, P. I. Y, L. Mateev, and N. Kilifarska. 3-D model for cosmic ray planetary ionisation in the middle atmosphere, Ann. Geophys., 2005, 23, 9, 3043-46.

19. Young, J. A. Static stability, in: J. R. Holton, J. A. Curry, J. A. Pyle (Editors), Encyclopaedia of Atmospheric Sciences. Academic Press, 2003, 5, 2114-20.

20. Schmidt, G. A., R. A. Ruedy, R. L. Miller, A. A. Lacis. Attribution of the present-day total greenhouse effect, Journal of Geophys. Res., 2010, 115, D20106, DOI:10.1029/2010JD014287.

21. Kilifarska, N., V. Bakhmutov, and G. Melny. Energetic particles influence on the southern hemisphere ozone variability, C. R. Acad. Bulg. Sci., 2013, 66, 11, 1613-22.

22. Kilifarska, N. and Tassev Y. Ozone profile response to the series of coronal mass ejections and severe geomagnetic storm in September 2017, C. R. Acad. Bulg. Sci., 2018, 71, 5, 663-71.

23. Nikolov, T. and N. Petrov, Main factors influencing climate change: A review, C. R. Acad. Bulg. Sci., 2014, 67, 11, 1455-76.

\title{
ВЛИЯНИЕ НА КОСМИЧЕСКИТЕ ЛЬЧИ И СЛЬНЧЕВАТА АКТИВНОСТ ВЪРХУ ДЬЛГОСРОЧНИТЕ ИЗМЕНЕНИЯ В КЛИМАТА НА ПЕЩЕРНИТЕ СИСТЕМИ
}

\author{
А. Стоев, ПГ. Стоева
}

\section{Резюме}

При анализа на влиянието на слънчевата активност върху климата акцентът се поставя върху температурните промени. Земната атмосфера е динамична система със сложни изменения в пространството и времето. Поради факта, че пещерите в Карст запазват дългосрочните промени в околната 
среда, изследването на атмосферните параметри в пещерите и техните вариации във времето става много важно през последната четвърт на века.

В тази статия изследваме еволюцията на температурата и налягането на приземния атмосферен слой във времето, измерени близо до входовете на две български карстови пещери: Снежанка (област Пазарджик) и Ухловица (област Смолян), през периода 2005-2017. Ние показваме, че топлинният и масовият обмен на въздуха на пещерите с околната среда има значителни изменения във времето. На годишна база термодинамичните параметри на наблюдаваните пещери са като на баротропичен флуид, при който пльтността на въздуха зависи само от атмосферното налягане. В резултат на това, налягането и температурата в пещерите се променят синхронно. Наблюдаваният 11-годишен цикъл може да се дължи на хелиосферната модулация на интензивността на галактическите космически льчи (GCR), които, от своя страна, модулират озона и влажността в близост до тропопаузата и съответно силата на парниковия ефект. Нашето изследване помага да се изясни влиянието на хелио-геофизичните фактори върху състоянието на ниската атмосфера. 